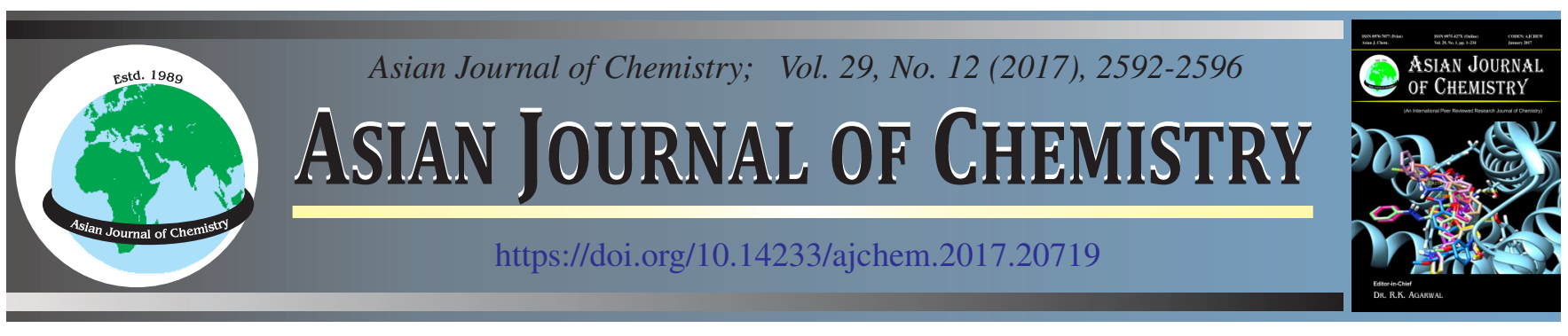

\title{
Reductometric Titration and Quantum Chemical Study of Oxalohydroxamic Acid for Determination of Manganese in Ores and Alloys
}

\author{
Sonalika Agrawal ${ }^{1}$, Fahmida Khan ${ }^{1}$, Dakeshwar Kumar Verma ${ }^{2, *}$ and Rakesh Kumar Sahu ${ }^{1}$
}

${ }^{1}$ Department of Chemistry, National Institute of Technology, Raipur-492 010, India

${ }^{2}$ Department of Chemistry, VEC Lakhanpur, Sarguja University Ambikapur-497 116, India

*Corresponding author: E-mail: dakeshwarverma@gmail.com

\begin{abstract}
Oxalohydroxamic acid has been employed as a reductometric titrant for the determination of manganese in $2 \mathrm{~N}$ sulphuric acid. Stoichiometry of the reaction is established. One mole of oxalohydroxamic acid was found to consume 12 equivalents of $\mathrm{KMnO}_{4}$. The titre values are obtained by second derivative plots of potentiometric titrations. The effect of diverse ions, temperature, time, sulphuric acid concentration and concentration of reacting substances on the stoichiometry of the reaction were studied. The results obtained are reproducible. This study also presents molecular orbital/density functional theory (MO/DFT) for calculations of the electronic structure and reducing property of oxalohydroxamic acid for metal determination. A good agreement is found between the predicted properties of oxalohydroxamic acid and experimental and theoretical results.

Keywords: Stoichiometry, Second derivative plot, Equivalents of oxidant, Density functional theory.
\end{abstract}

\section{INTRODUCTION}

Hydroxamic acids are excellent analytical reagents for organic and inorganic analysis. Extensive works have been carried out on their synthesis [1], complexation with metal ions [2], gravimetry [3], colorimetry [4], kinetics [5-9], spectrophotometry [10] and medical applications [11-14]. Benzohydroxamic acid was used as a reductometric titrant for determination of manganese, chromium [15] and cerium, uranium [16]. The proposed method is based on the reduction property of aliphatic hydroxamic acid i.e. oxalohydroxamic acid (OHA).

Manganese is one of the most widely used metal in the industries. Manganese is used to form an alloy in the steel which results in improvement of better properties such as toughness, stiffness, wear resistance, hardness and most important strength. It is used by the steel industry, as a deoxidizing and desulfurizing additive and as an alloying constituent. It is also often alloyed with other metals such as aluminium and copper to reduce corrosion [17-19]. The reactions of permanganate are interesting because of the several oxidation states to which the manganese can be reduced. Manganese species having oxidation numbers between +1 and +7 are well known. The reduction of manganese(VII) to a lower oxidation state depends on the reaction media. Generally, titrations are carried out in acid medium.

For the determination of manganese several methods have been developed and reported. Out of which most widely adopted is titrimetric procedure to oxidize $\mathrm{Mn}$ (II) to $\mathrm{Mn}$ (VII) with persulphate in sulphuric acid medium and titrate the Mn(VII) with As(III). During our studies on the oxidation of oxalohydroxamic acid with $\mathrm{KMnO}_{4}$, it was observed that 12 equivalents of oxidant are consumed by one mole of the reductant. In this reaction, $\mathrm{KMnO}_{4}$ is quantitatively reduced to $\mathrm{Mn}(\mathrm{II})$ in $2 \mathrm{~N}$ $\mathrm{H}_{2} \mathrm{SO}_{4}$ and permanganate is titrated with standard oxalohydroxamic acid solution. The reaction is instantaneous and stoichiometric. This proposed titrimetric method has been successfully employed for the determination of manganese in various ores and alloys.

In present study quantum chemical studies based on DFT theory has been employed to study the electronic properties of organic molecules possibly relevant to theirreactivity towards metal ion(s) $[20,21]$. To characterize the reducing property of oxalohydroxamic acid, molecular orbital calculations are performed, which are helpful to obtain the interaction mechanism of organic molecules with metal ion(s).

\section{EXPERIMENTAL}

Preparation of manganese(VII): A stock solution of Mn(VII) was prepared by dissolving a weighed quantity of G.R. grade potassium permanganate (Merck, India) in Millipore purified water and diluted to mark in a volumetric flask and was standardized against arsenious oxide before use [22]. 
Preparation of hydroxamic acid solution: Oxalohydroxamic acid was prepared and purified by literature procedures $[23,24]$. Standard solution of hydroxamic acid was prepared by dissolving accurately weighed quantity of pure oxalohydroxamic acid in Millipore purified water and diluting to a known volume.

Preparation of standard sulphuric acid solution: Standard solution of dilute sulphuric acid was prepared in Millipore water and was standardized with sodium carbonate [25].

Metal ions: Solutions of various metal ions used in the interference studies were prepared according to West's procedure $[26,27]$.

Preparation of standard samples: An accurately weighed quantity of sample (0.1-0.2 g) was dissolved in $20 \mathrm{~mL}$ of aquaregia. To the cooled solution $5 \mathrm{~mL}$ of concentrated sulphuric acid was added and the solution was heated till dense white fumes appeared. Solutions of ores and alloys containing more than $5 \%$ Mn were diluted to standard volume after proper cooling at this stage and aliquots were used. The sample (or its aliquot) was diluted to $100 \mathrm{~mL}$ and $10 \mathrm{~mL}$ of $1 \% \mathrm{AgNO}_{3}$ solution and 0.5 to $1.0 \mathrm{~g}$ of potassium persulphate were added, followed by $5 \mathrm{~mL}$ of conc. $\mathrm{H}_{2} \mathrm{SO}_{4}$ and the mixture was heated. When the oxidation was completed the mixture was gently boiled to decompose the excess of persul-phate. The solution was cooled to room temperature and titrated with oxalohydroxamic solution, standardized by using it to titrate a standard permanganate solution in $2 \mathrm{~N} \mathrm{H}_{2} \mathrm{SO}_{4}$ medium. The end point was signalled by the disappearance of the colour of permanganate. Mettler Toledo AL 204 analytical top loading balance was used for weighing and purified water was obtained from Elix Essential 10 Millipore water purifier.

$$
1 \mathrm{~mL} \text { of } 0.1 \mathrm{M} \mathrm{OHA}=65.926 \mathrm{mg} \mathrm{Mn}
$$

Autotitrator: All titrations were performed using an auto titrator Model AT-97 manufactured by Mayura Analytical Pvt. Ltd., Bangalore, India. This auto titration system consists of a motor-driven titrant dispenser, a mechanical stirrer and electrodes coupled to a $\mathrm{pH} / \mathrm{ion}$ analyser and controlled by personal computer for automatic titration and data acquisition and processing. The titrant from the reservoir was delivered accurately through a calibrated dispenser in the titration vessel. The e.m.f. readings were recorded with the autotitrator using platinum electrode as indicator electrode and saturated calomel electrode as reference electrode.

Theoretical study: Gaussian 09 (G 09) software package is used for quantum chemical calculation of oxalohydroxamic acid with geometrically optimized structure. The backe's three parameters hybrid exchange functional and Lee-Yang-Parr nonlocal correlation function [x] (B3LYP) as well as 3-21G basic set were employed for calculations. The theoretical parameters such as lowest unoccupied molecular orbital (LUMO) energies, highest occupied molecular orbital (HOMO) energies, energy gap $\Delta \mathrm{E}\left(\mathrm{E}_{\text {Hомо }}-\mathrm{E}_{\mathrm{Lumo}}\right)$, etc. were calculated.

Procedure: An aliquot of $\mathrm{Mn}(\mathrm{VII})$ solution $(10 \mathrm{~mL})$ containing $14 \mathrm{mg}$ manganese was taken in a $100 \mathrm{~mL}$ beaker and required standard sulphuric acid solution was added so that the acidity was adjusted to $2 \mathrm{~N}$ in a total volume of $50 \mathrm{~mL}$. It was then titrated potentiometrically with standard oxalohydroxamic acid solution added from a micro burette.

\section{RESULTS AND DISCUSSION}

The structure of oxalohydroxamic acid (OHA) is shown in Fig. 1. The oxalohydroxamic acid is characterized by Fourier transform infrared (FTIR) spectroscopy is presented in Fig. 2. FTIR spectra of oxalohydroxamic acid represent the absorption band observed at $\lambda_{\max } 3271.87 \mathrm{~cm}^{-1}$ arises due to N-H stretching vibration. The $\mathrm{O}-\mathrm{H}$ bonds in crystalline oxalohydroxamic acid are strongly hydrogen bonded and thus associated vibrational bands are observed neat $\lambda_{\max } 3184-3074 \mathrm{~cm}^{-1}$ and $\lambda_{\max } 2862$ $\mathrm{cm}^{-1}$. The bands at $\lambda_{\max } 1654.81 \mathrm{~cm}^{-1}$ arise due to $\mathrm{C}=\mathrm{O}$ stretching vibration. The absorption bands $1442.14,1380,1227.27$, 1099 and $846 \mathrm{~cm}^{-1}$ arises from the vibrations of $\mathrm{N}-\mathrm{H}$ bending, $\mathrm{OH}$ bending, OCN stretching, N-O stretching and C-NO bending, respectively. The observations revealed the presence of -NHOH groups in oxalohydroxamic acid.

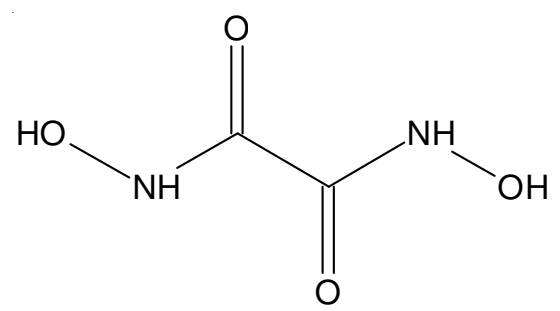

Fig. 1. Structure of oxalohydroxamic acid (OHA)

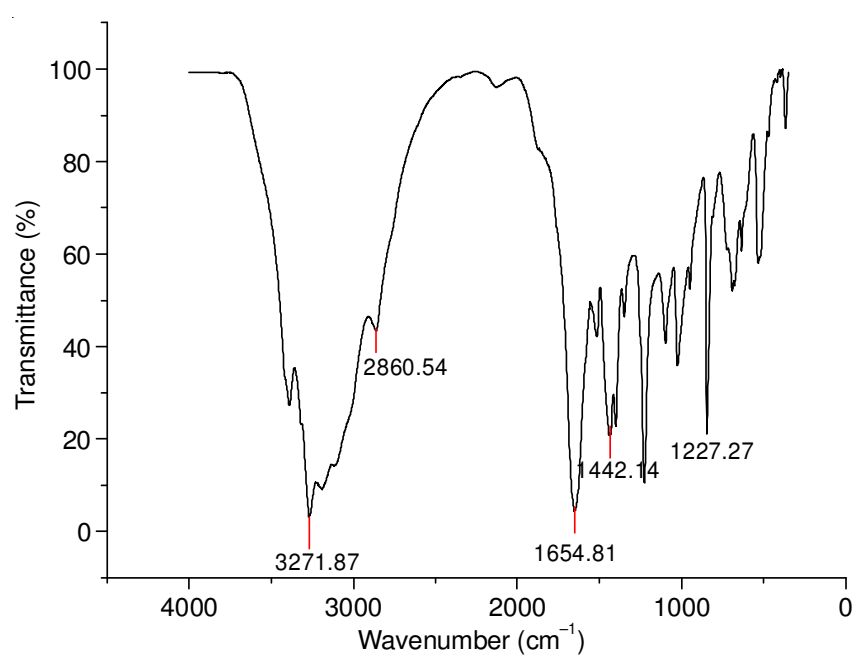

Fig. 2. FTIR spectra of oxalohydroxamic acid

Effect of sulphuric acid concentration: To study the effect of sulphuric acid concentration on the reaction potentiometric titrations were carried out. The results are given in Table1. The titration curves are shown in Fig. 4. It can be seen from the observations that there is no noticeable change in the number of equivalents of potassium permanganate in the acidity range of 1-6 N. It was observed that though the reaction was stoichiometric in $1 \mathrm{~N}$ sulphuric acid the sharp end point is obtained in $2 \mathrm{~N}$ acidity. Therefore, all experiments were carried out in $2 \mathrm{~N}$ sulphuric acid.

Effect of temperature, concentration of the reacting substances and time: To study the effect of temperature and concentration of the reacting substances on the reaction, visual and potentiometric titrations were carried out. The results are presented in Tables 2 and 3. To study the effect of time, the 


\begin{tabular}{|c|c|c|}
\hline \multicolumn{3}{|c|}{$\begin{array}{c}\text { TABLE-1 } \\
\text { EFFECT OF SULPHURIC ACID CONCENTRATION; } \\
(\mathrm{CONHOH})_{2}=5.002 \times 10^{-3} \mathrm{M} ; \mathrm{KMnO}_{4}=2.497 \times 10^{-2} \mathrm{M} \\
10 \mathrm{~mL} \text { titrated; } \mathrm{H}_{2} \mathrm{SO}_{4}=8.260 \mathrm{~N} ; \text { Total volume }=50 \mathrm{~mL}\end{array}$} \\
\hline Acidity, $\mathrm{H}_{2} \mathrm{SO}_{4}$ & $\mathrm{OHA}(\mathrm{mL}) *$ & $\begin{array}{l}\text { Equivalents of } \mathrm{Mn}(\mathrm{VII}) \text { per } \\
\text { mole of } \mathrm{OHA}\end{array}$ \\
\hline 1 & 4.167 & 11.98 \\
\hline 2 & 4.160 & 12.00 \\
\hline 3 & 4.160 & 12.00 \\
\hline 4 & 4.153 & 12.02 \\
\hline 5 & 4.163 & 11.99 \\
\hline 6 & 4.150 & 12.03 \\
\hline \multicolumn{3}{|c|}{$\begin{array}{l}\text { *Values obtained from second derivative plots of potentiometric } \\
\text { titration. }\end{array}$} \\
\hline \multicolumn{3}{|c|}{$\begin{array}{c}\text { TABLE-2 } \\
\text { EFFECT OF TEMPERATURE ON THE DETERMINATION OF } \\
\text { Mn(VII); }(\text { CONHOH })_{2}=5.031 \times 10^{-3} \mathrm{M} ; \mathrm{KMnO}_{4}=2.521 \times 10^{-2} \mathrm{M} \text {; } \\
10 \mathrm{~mL} \text { titrated; } \mathrm{H}_{2} \mathrm{SO}_{4}=8.260 \mathrm{~N} ; \text { Total volume }=50 \mathrm{~mL}\end{array}$} \\
\hline Temperature $\left({ }^{\circ} \mathrm{C}\right)$ & $\begin{array}{l}\text { Volume of } \\
\text { OHA (mL) }\end{array}$ & $\begin{array}{l}\text { Equivalents of } \mathrm{Mn}(\mathrm{VII}) \\
\text { per mole of } \mathrm{OHA}\end{array}$ \\
\hline 25 & 4.19 & 11.97 \\
\hline 30 & 4.17 & 12.01 \\
\hline 35 & 4.18 & 12.00 \\
\hline 40 & 4.18 & 12.00 \\
\hline 45 & 4.16 & 12.05 \\
\hline 50 & 4.16 & 12.05 \\
\hline
\end{tabular}

\section{TABLE-3}

EFFECT OF CONCENTRATION OF REACTING SUBSTANCES; $\mathrm{KMnO}_{4}=2.521 \times 10^{-2} \mathrm{~N} ; \mathrm{H}_{2} \mathrm{SO}_{4}=8.260 \mathrm{~N}$; Total volume $=50 \mathrm{~mL}$

\begin{tabular}{ccccc}
\hline $\begin{array}{c}\text { Conc. of } \\
\text { OHA }\end{array}$ & $\begin{array}{c}\text { Volume of } \\
\mathrm{Mn}(\mathrm{VII}) \\
(\mathrm{mL})\end{array}$ & $\begin{array}{c}\text { Volume of } \\
\mathrm{H}_{2} \mathrm{SO}_{4} \\
\text { added } \\
(\mathrm{mL})\end{array}$ & $\begin{array}{c}\text { Volume of } \\
\text { OHA }(\mathrm{mL})\end{array}$ & $\begin{array}{c}\text { Equivalents } \\
\text { of Mn(VII) } \\
\text { per mole of } \\
\text { OHA }\end{array}$ \\
\hline $3.103 \times 10^{-3}$ & 5.0 & 10.90 & 3.42 & 11.88 \\
$\mathrm{M}(0.06075$ & 10.0 & 9.69 & 6.76 & 12.02 \\
$\mathrm{~g} / 250 \mathrm{~mL})$ & 15.0 & 8.47 & 10.16 & 12.00 \\
& 20.0 & 7.26 & 13.50 & 12.04 \\
\hline $4.018 \times 10^{-3}$ & 5.0 & 10.90 & 2.62 & 11.97 \\
$\mathrm{M}(0.08273$ & 10.0 & 9.69 & 5.23 & 12.00 \\
$\mathrm{~g} / 250 \mathrm{~mL})$ & 15.0 & 8.47 & 7.83 & 12.02 \\
\hline $5.031 \times 10^{-3}$ & 20.0 & 7.26 & 10.43 & 12.03 \\
$\mathrm{M}(0.15006$ & 10.0 & 10.90 & 2.09 & 11.99 \\
$\mathrm{~g} / 250 \mathrm{~mL})$ & 15.0 & 8.69 & 4.17 & 12.02 \\
& 20.0 & 7.26 & 8.47 & 12.01 \\
\hline
\end{tabular}

reaction mixtures were allowed to stand for different time intervals and then titrated visually with standard iron(II) solution. The results are presented in Table-4. The results show that temperature, concentration of the reacting substances and time does not have any significant effect on the reactions.

Interference of metal ions: The interference of cations like $\mathrm{Cu}(\mathrm{II}), \mathrm{Zn}(\mathrm{II}), \mathrm{Ni}(\mathrm{II}), \mathrm{Co}(\mathrm{II}), \mathrm{Fe}(\mathrm{III}), \mathrm{Ti}(\mathrm{IV}), \mathrm{V}(\mathrm{V}), \mathrm{U}(\mathrm{VI})$ and $\mathrm{Cr}(\mathrm{VI})$ were studied by adding varying milligram quantities of these ions to $13.63 \mathrm{mg}$ of $\mathrm{Mn}(\mathrm{VII})$ in $2 \mathrm{~N} \mathrm{H}_{2} \mathrm{SO}_{4}$ and then titrating with oxalohydroxamic acid to a visual end point. The results are recorded in Table-5. It can be concluded from the results that with the exception of $\mathrm{Cr}(\mathrm{VI})$, the method is free from interference of many ions. As $\mathrm{Cr}(\mathrm{VI})$ fairly interferes with the determination detailed studies were made with varying concentrations of $\mathrm{Mn}(\mathrm{VII})$ and $\mathrm{Cr}(\mathrm{VI})$. It was observed that at lower levels of manganese i.e., $0.1 \mathrm{mg}$ or less, $\mathrm{Cr}(\mathrm{VI})$ did not

\begin{tabular}{ccc} 
TABLE-4 & EFFECT OF TIME \\
& Back titration of excess Mn(VII) with iron(II) \\
$(\mathrm{CONHOH})_{2}=5.020 \times 10^{-3} \mathrm{M} ; 10 \mathrm{~mL}$ added; $\mathrm{KMnO}_{4}=2.521 \times$ \\
$10^{-2} \mathrm{~N} ;$ Volume of $\mathrm{Mn}(\mathrm{VII})=50 \mathrm{~mL}$; Total volume $=100 \mathrm{~mL}$ \\
\hline \multirow{2}{*}{ Time $(\mathrm{h})$} & $\begin{array}{c}\text { Volume of ferrous } \\
\text { ammonium sulphate }(\mathrm{mL})\end{array}$ & $\begin{array}{c}\text { Equivalents of } \mathrm{Mn}(\mathrm{VII}) \\
\text { per mole of OHA }\end{array}$ \\
\hline 0.00 & 4.50 & 12.00 \\
0.25 & 4.50 & 12.00 \\
0.50 & 4.55 & 11.97 \\
1.00 & 4.45 & 12.02 \\
5.00 & 4.40 & 12.04 \\
\hline
\end{tabular}

\begin{tabular}{|c|c|c|c|c|c|c|c|}
\hline \multicolumn{8}{|c|}{$\begin{array}{c}\text { TABLE-5 } \\
\text { INTERFERENCE OF FOREIGN IONS } \\
(\mathrm{CONHOH})_{2}=5.0144 \times 10^{-3} \mathrm{M} ; \mathrm{KMnO}_{4}=4.313 \times 10^{-2} \mathrm{~N} ; \text { Acidity }= \\
2 \mathrm{~N} \mathrm{H}_{2} \mathrm{SO}_{4} ; \text { Volume of } \mathrm{Mn}(\mathrm{VII})=10 \mathrm{~mL} ; \text { Total volume }=50 \mathrm{~mL}\end{array}$} \\
\hline \multirow{2}{*}{$\begin{array}{l}\text { Addenda } \\
\text { ions }\end{array}$} & \multicolumn{2}{|c|}{$\begin{array}{l}\text { Amount } \\
\text { added }\end{array}$} & \multirow{2}{*}{$\begin{array}{l}\text { OHA } \\
(\mathrm{mL})\end{array}$} & \multirow{2}{*}{$\begin{array}{c}\text { Addenda } \\
\text { ions }\end{array}$} & \multicolumn{2}{|c|}{$\begin{array}{c}\text { Amount } \\
\text { added }\end{array}$} & \multirow{2}{*}{$\begin{array}{l}\text { OHA } \\
(\mathrm{mL})\end{array}$} \\
\hline & $\mathrm{mL}$ & $\mathrm{mg}$ & & & $\mathrm{mL}$ & $\mathrm{mg}$ & \\
\hline None & - & - & 7.17 & None & - & - & 7.17 \\
\hline \multirow{3}{*}{$\mathrm{Cu}(\mathrm{II})$} & 1.0 & 10 & 7.17 & \multirow{3}{*}{$\mathrm{Mn}(\mathrm{VI})$} & 0.5 & 5 & 7.17 \\
\hline & 2.0 & 20 & 7.17 & & 1.0 & 10 & 7.15 \\
\hline & 3.0 & 30 & 7.17 & & 2.0 & 20 & 7.15 \\
\hline \multirow{3}{*}{$\mathrm{Ni}(\mathrm{II})$} & 1.0 & 10 & 7.17 & \multirow{3}{*}{$\mathrm{V}(\mathrm{V})$} & 0.5 & 05 & 6.47 \\
\hline & 2.0 & 20 & 7.17 & & 1.0 & 10 & 7.56 \\
\hline & 3.0 & 30 & 7.15 & & 2.0 & 20 & 9.40 \\
\hline \multirow{3}{*}{$\mathrm{Zn}(\mathrm{II})$} & 1.0 & 10 & 7.17 & \multirow{3}{*}{$\mathrm{Cr}(\mathrm{VI})$} & 1.0 & 10 & 7.17 \\
\hline & 2.0 & 20 & 7.19 & & 2.0 & 20 & 13.45 \\
\hline & 3.0 & 30 & 7.17 & & 2.5 & 25 & 25.12 \\
\hline \multirow{4}{*}{ U(IV) } & 0.5 & 5 & 7.17 & \multirow{4}{*}{$\mathrm{Co}(\mathrm{II})$} & 0.5 & 5 & 7.17 \\
\hline & 1.0 & 10 & 7.17 & & 1.0 & 10 & 7.17 \\
\hline & 2.0 & 20 & 7.18 & & 1.5 & 15 & 7.17 \\
\hline & 3.0 & 30 & 7.15 & & 2.0 & 20 & 7.30 \\
\hline \multirow{4}{*}{$\mathrm{Ti}(\mathrm{IV})$} & 0.5 & 5 & 7.17 & \multirow{4}{*}{$\mathrm{Fe}(\mathrm{III})$} & 0.5 & 5 & 7.17 \\
\hline & 1.0 & 10 & 7.17 & & 1.0 & 10 & 7.17 \\
\hline & 2.0 & 20 & 7.17 & & 1.5 & 15 & 7.17 \\
\hline & 3.0 & 30 & 7.66 & & 2.0 & 20 & 7.28 \\
\hline
\end{tabular}

interfere even if present in $10 \mathrm{mg}$ amount, but with increasing concentration of $\mathrm{Mn}$ the interference also increased. For $1 \mathrm{mg}$ of $\mathrm{Mn}$ the tolerance limit for chromium was found to be $6 \mathrm{mg}$. For $2.5 \mathrm{mg}$ of $\mathrm{Mn}$, it was $12 \mathrm{mg}$ and for $5 \mathrm{mg}$ of $\mathrm{Mn}$, it was 14 $\mathrm{mg}$. The chromium can be presumed to interfere by oxidizing $\mathrm{Mn}$ (II) to $\mathrm{Mn}$ (III) [28]. Chromium is expected to interfere according to the reaction:

$$
6 \mathrm{Mn}^{2+}+\mathrm{Cr}_{2} \mathrm{O}_{7}^{2-}+14 \mathrm{H}^{+} \longrightarrow 6 \mathrm{Mn}^{3+}+2 \mathrm{Cr}^{3+}+7 \mathrm{H}_{2} \mathrm{O}
$$

Therefore, the determination of $\mathrm{Mn}$ in ores and alloys can be done without any difficulty in absence of chromium.

Applications of proposed method: The established stoichiometry of Mn(VII) - OHA reaction in $2 \mathrm{~N}$ sulphuric acid medium has been applied for the determination of manganese. The proposed method was applied for the determination of manganese in the standard reference materials, e.g. BCS-CRM no.113, Cast Austenitic manganese steel and pyrolusite. The results of the analysis of standard reference materials are recorded in Table- 6 . The determined values of percentage of manganese in these standard materials are in good agreement with the reported values.

Quantum chemical studies: The density function theory (DFT) is very important theoretical model used in elucidating the chemistry of molecules and science of solids [29]. Various 
Vol. 29, No. 12 (2017) Reductometric Titration and Quantum Chemical Study of Oxalohydroxamic Acid for Determination of Manganese 2595

\begin{tabular}{|c|c|c|c|}
\hline \multicolumn{4}{|c|}{$\begin{array}{c}\text { TABLE-6 } \\
\text { ANALYSIS OF STANDARD REFERENCE MATERIAL } \\
(\text { CONHOH })_{2}=2.235 \times 10^{-2} \mathrm{M}\end{array}$} \\
\hline $\begin{array}{l}\text { Name and product } \\
\text { code of alloys }\end{array}$ & $\begin{array}{c}\text { Sample } \\
\text { taken (mg) }\end{array}$ & $\begin{array}{l}\text { Theoretical } \\
\text { value }(\%)\end{array}$ & $\begin{array}{l}\text { Observed } \\
\text { value (\%) }\end{array}$ \\
\hline BCS-CRM no. 113 & 660.46 & 1.20 & 1.178 \\
\hline $\begin{array}{l}\text { Cast austenitic } \\
\text { manganese steel }\end{array}$ & 470.908 & $11.50-14.50$ & 12.885 \\
\hline Pyrolusite & 205.85 & 25.57 & 25.44 \\
\hline
\end{tabular}

chemical concepts have been correlated using framework of density function theory (DFT) [30]. One of the most important parameter, electron density calculated in DFT upon which most of the chemical quantities are expressed [31]. Density function theory has been widely used to describe the structural nature of the molecules in recent time [32]. Moreover, DFT is considered as an effective technique to analyze the interaction between metal and organic molecules.

Various theoretical parameters viz. lowest unoccupied molecular orbital ( $\left.\mathrm{E}_{\mathrm{LUMO}}\right)$, highest occupied molecular orbital $\left(\mathrm{E}_{\mathrm{HOMO}}\right)$ and the energy gap $\Delta \mathrm{E}\left(\mathrm{E}_{\mathrm{LUMO}}-\mathrm{E}_{\mathrm{HOMO}}\right)$ were calculated from optimized structure of OHA. These parameters were used to explain the interaction between OHA with metal ion(s) [29]. Therefore, quantum chemical using DFT was used to explain the reducing behaviour of OHA discussed in the present investigation. Distribution of frontier orbitals (HOMO, LUMO) was considered for determining the active sites of organic molecules for interaction. According the classical chemical theory, there are two types of chemical interactions (i) orbital interaction and (ii) electrostatic interaction. The driving force of electrostatic interactions in the molecules has been proven that local electron density are important in chemical reactions of organic compounds [33]. The graphic presentation of optimized structure, $\mathrm{E}_{\mathrm{Lumo}}$ and $\mathrm{E}_{\text {номо }}$ for OHA shown in Fig. 3(a-c). These parameters give the information about the reactive behaviour of OHA (Table-7). High $\mathrm{E}_{\mathrm{HOMO}}$ energy of $\mathrm{OHA}$ indicates the higher electron donating capacity to the metal ion with empty molecular orbital of low energy. The lower $\mathrm{E}_{\mathrm{Lumo}}$ value indicated that OHA can easily accept electrons from metal ions by back pi bonding [34]. The energy gap $(\Delta \mathrm{E})$ between $\mathrm{E}_{\mathrm{Lumo}}$ and $\mathrm{E}_{\text {номо }}\left(\Delta \mathrm{E}=\mathrm{E}_{\mathrm{LUMO}}\right.$ and $\mathrm{E}_{\text {Hомо }}$ ) was also determine. Low values of energy gap will provide good interaction ability of $\mathrm{OHA}$, because excitation energy will be low to remove an electron from last orbital [20].

It could be seen from Fig. 3(b) \& (c) that OHA have almost similar LUMO and HOMO distributions, which is due to presence of oxygen and nitrogen atoms. Therefore interaction

\begin{tabular}{ccccc} 
TABLE-7 \\
SOME MOLECULAR PROPERTIES OF OHA CALCULATED \\
USING DFT AT THE B3LYP/3-21G BASIC SET LEVEL \\
\hline $\mathrm{E}_{\text {номо }}(\mathrm{eV})$ & $\mathrm{E}_{\text {LUMо }}(\mathrm{eV})$ & $\Delta \mathrm{E}(\mathrm{eV})$ & $\eta$ & $\omega$ \\
\hline-0.237 & -0.065 & 0.172 & 0.086 & 11.62 \\
\hline
\end{tabular}

takes place between bonded electrons on hetero atoms $(\mathrm{O}, \mathrm{N})$ of OHA and unoccupied d-orbitals of Mn atom. Usually higher values of $\mathrm{E}_{\text {номо }}$ are likely to show an ability of molecule to donate electrons to suitable acceptor. From Table-7 it is apparent that $\mathrm{OHA}$ has higher value of $\mathrm{E}_{\mathrm{HOMO}}$ indicates the good interaction ability towards metal ion. A molecule with low HOMOLUMO energy gap $(\Delta \mathrm{E})$ is more polarized and usually associated with low kinetic stability, high chemical reactivity and is designated soft molecule [35]. Molecule with lowest hardness $(\eta)$ and greatest softness $(\omega)$ show good interaction ability to metal ions/surface.

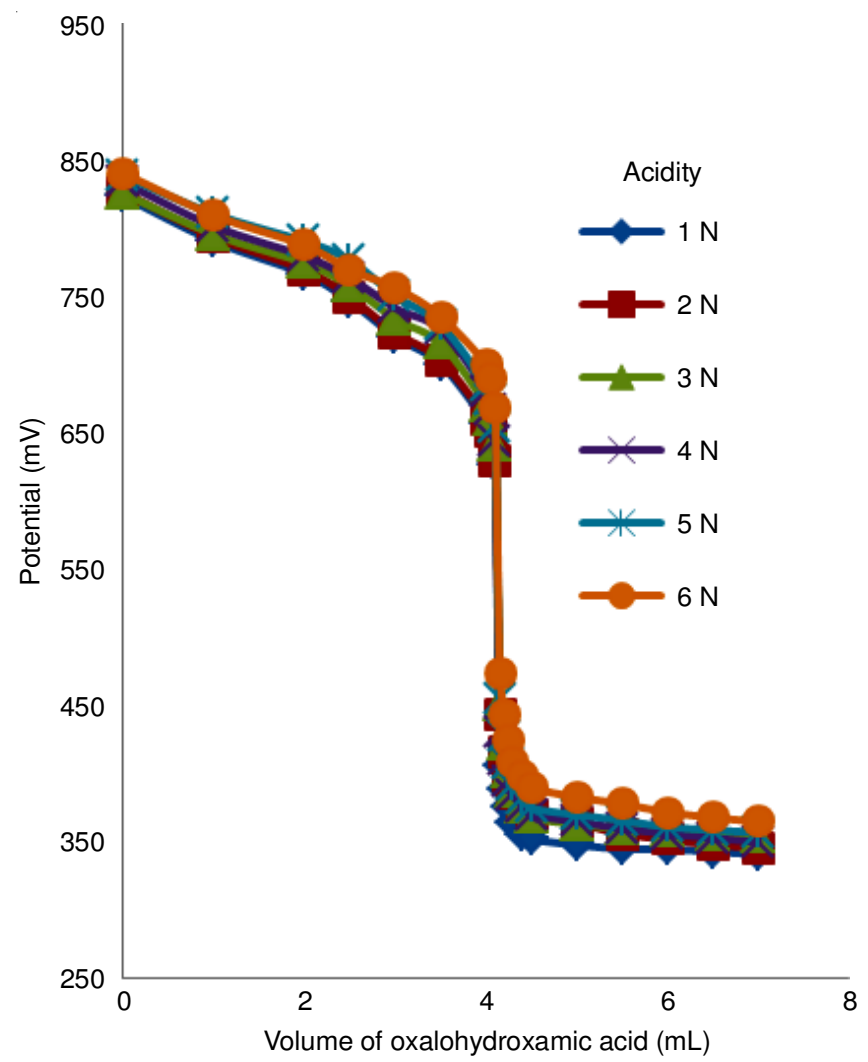

Fig. 4. Titration of Mn(VII) with OHA in different sulphuric acid concentrations
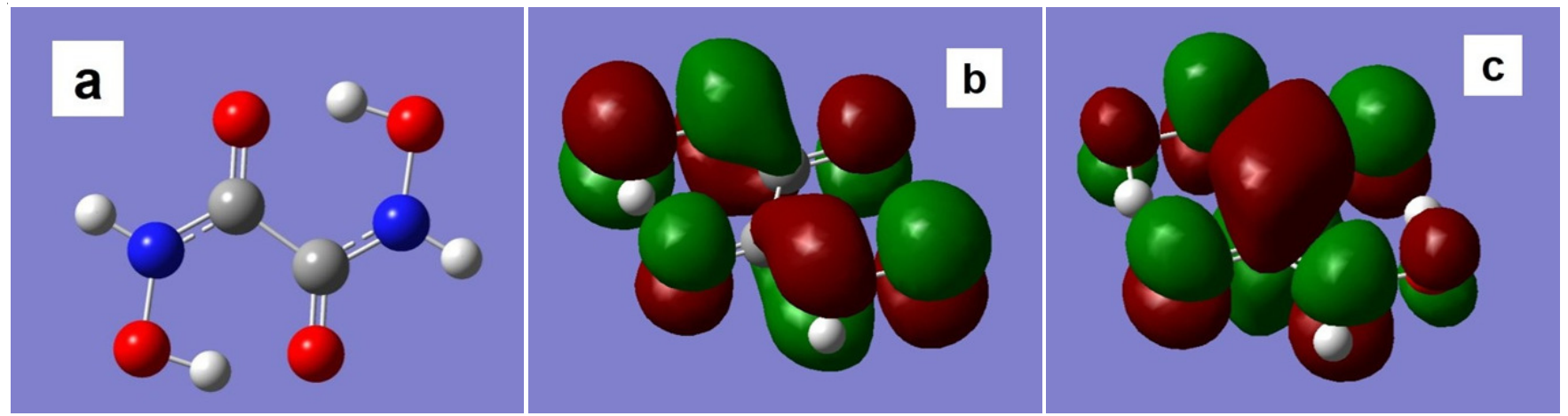

Fig. 3. (a) Optimized structure, (b) HOMO and (c) LUMO density of OHA using DFT at the B3LYP/3-21G basic set level 


\section{Conclusion}

The developed method is based on the reduction behaviour of hydroxamic acid in acidic medium.It is an improved titrimetric method for the establishment of $\mathrm{Mn}$ (VII) -OHA reaction stoichiometry in $2 \mathrm{~N}$ sulphuric acid media. It is a rapid and précised procedure as the reaction is instantaneous at room temperature. The proposed method has the advantage over the earlier reported hydroxamic acid that better number of equivalents is obtained sharply and precisely which facilitates the accurate estimation of $\mathrm{Mn}$ in alloys. Data obtained from quantum chemical calculations by using the DFT at the B3LYP/ 3-21G basic set level, a correlation between parameters related to the molecular and electronic of $\mathrm{OHA}$ and its reduction ability could be established. Comparison of experimental and theoretical data reveals the good correlation confirming the credibility of the method employed in the present investigation.

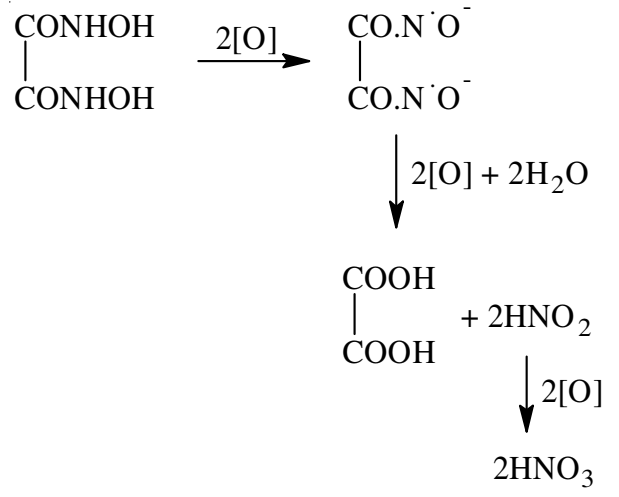

\section{REFERENCES}

1. A. Brik, C.-Y. Wu and C.-H. Wong, Org. Biomol. Chem., 4, 1446 (2006); https://doi.org/10.1039/b600055j.

2. D.Y. Chung and E.H. Lee, Bull. Korean Chem. Soc., 26, 1692 (2005); https://doi.org/10.5012/bkcs.2005.26.11.1692.

3. E. Farkas, E.A. Enyedy, G. Micera and E. Garribba, Polyhedron, 19, 1727 (2000); https://doi.org/10.1016/S0277-5387(00)00453-8.

4. I.P. Alimarin, F.P. Sudakov and B.G. Golovkin, Russ. Chem. Rev., 31, 466 (1962);

https://doi.org/10.1070/RC1962v031n08ABEH001306.

5. F.P.L. Andrieux, C. Boxall and R.J. Taylor, J. Solution Chem., 36, 1201 (2007); https://doi.org/10.1007/s10953-007-9183-9.

6. R. Brammer, J. Buckels and S. Bramhall, Int. J. Clin. Pract., 54, 373 (2000).

7. D.A. Brown, L.P. Cuffe, N.J. Fitzpatrick and Á.T. Ryan, Inorg. Chem., 43, 297 (2004); https://doi.org/10.1021/ic034432x.

8. J.E. Birkett, M.J. Carrott, O.D. Fox, C.J. Jones, C.J. Maher, C.V. Roube, R.J. Taylor and D.A. Woodhead, Nucl. Sci. Technol., 44, 337 (2007); https://doi.org/10.1080/18811248.2007.9711291.

9. R. Chiarizia, P.R. Danesi and S. Fornarini, J. Inorg. Nucl. Chem., 41, 1465 (1979); https://doi.org/10.1016/0022-1902(79)80213-4

10. A.K. Majumdar, N-Benzoylphenylhydroxylamine and Its Analogues, Pergamon Press, Oxford, edn 1, pp. 107(1972).

11. R. Codd, Coord. Chem. Rev., 252, 1387 (2008); https://doi.org/10.1016/j.ccr.2007.08.001.
12. H. Mishra, A.L. Parrill and J.S. Williamson, Antimicrob. Agents Chemother, 46, 2613 (2002); https://doi.org/10.1128/AAC.46.8.2613-2618.2002.

13. N. Braich and R. Codd, Analyst, 133, 877 (2008); https://doi.org/10.1039/b802355g.

14. J. Liu, D. Obando, L.G. Schipanski, L.K. Groebler, P.K. Witting, D.S. Kalinowski, D.R. Richardson and R. Codd, J. Med. Chem., 53, 1370 (2010); https://doi.org/10.1021/jm9016703.

15. M.K. Ahmed and C.S. Rao, Talanta, 25, 708 (1978); https://doi.org/10.1016/0039-9140(78)80181-7.

16. R.J. Taylor, I. May, A.L. Wallwork, I.S. Denniss, N.J. Hill, B.Y. Galkin, B.Y. Zilberman and Y.S. Fedorov, J. Alloys Comp., 271-273, 534 (1998); https://doi.org/10.1016/S0925-8388(98)00146-7.

17. G.B. Gerber, A. L'eonard and P. Hantson, Crit. Rev. Oncol. Hematol., 42, 25 (2002); https://doi.org/10.1016/S1040-8428(01)00178-0.

18. R. Baetty, The Rlements: Manganese, Marshal Cavendish Corporation: New York, pp. 32(2004).

19. WHO, Air Quality Guidelines for Europe, World Health Organisation, Regional Office for Europe: Copenhagen, edn 2, pp. 288 (2001).

20. G. Gece, Corros. Sci., 50, 2981 (2008); https://doi.org/10.1016/j.corsci.2008.08.043.

21. M.J. Frisch, G.W. Trucks, H.B. Schlegel, G.E. Scuseria, M.A. Robb, J.R. Cheeseman, G. Scalmani, V. Barone, B. Mennucci, G.A. Petersson, H. Nakatsuji, M. Caricato, X. Li, H.P. Hratchian, A.F. Izmaylov, J. Bloino, G. Zheng, J.L. Sonnenberg, M. Hada, M. Ehara, K. Toyota, R. Fukuda, J. Hasegawa, M. Ishida, T. Nakajima, Y. Honda, O. Kitao, H. Nakai, T. Vreven, J.A. Montgomery Jr., J.E. Peralta, F. Ogliaro, M. Bearpark, J.J. Heyd, E. Brothers, K.N. Kudin, V.N. Staroverov, R. Kobayashi, J. Normand, K. Raghavachari, A. Rendell, J.C. Burant, S.S. Iyengar, J. Tomasi, M. Cossi, N. Rega, J.M. Millam, M. Klene, J.E. Knox, J.B. Cross, V. Bakken, C. Adamo, J. Jaramillo, R. Gomperts, R.E. Stratmann, O. Yazyev, A.J. Austin, R. Cammi, C. Pomelli, J.W. Ochterski, R.L. Martin, K. Morokuma, V.G. Zakrzewski, G.A. Voth, P. Salvador, J.J. Dannenberg, S. Dapprich, A.D. Daniels, O. Farkas, J.B. Foresman, J.V. Ortiz, J. Cioslowski and D.J. Fox, Gaussian, Inc., Wallingford CT (2009).

22. Vogel's Textbook of Quantitative Inorganic Analysis, ELBS New York, Section X, edn 4, p. 351 (1978).

23. W.B. Renfrow Jr. and C.R. Hauser, J. Am. Chem. Soc., 59, 2308 (1937); https://doi.org/10.1021/ja01290a064.

24. S. Agrawal, F. Khan and S. Ganesh, Chem. Mater. Res., 2, 58 (2012).

25. E.W. Balis, L.B. Bronk, H.A. Liebhafsky and H.G. Pfeiffer, Anal. Chem., 27, 1173 (1955); https://doi.org/10.1021/ac60103a041.

26. F. Khatoon, Ph.D Thesis, Pt. Ravishankar Shukla University, Raipur India (1984).

27. P.W. West, J. Chem. Educ., 18, 528 (1941); https://doi.org/10.1021/ed018p528.

28. G.G. Rao and P.K. Rao, Talanta, 10, 1251 (1963); https://doi.org/10.1016/0039-9140(63)80185-X

29. C.B. Verma, M.A. Quraishi and A. Singh, J. Taiwan Inst. Chem. Eng., 49, 229 (2015); https://doi.org/10.1016/i.jtice.2014.11.029.

30. H. Chermette, J. Comput. Chem., 20, 129 (1999); https://doi.org/10.1002/(SICI)1096-987X(19990115)20:1<129::AIDJCC13>3.0.CO;2-A

31. R.G. Parr and W. Yang, Density Functional Theory of Atoms and Molecules, Oxford University Press, Oxford (1989).

32. E.E. Ebenso, T. Arslan, F. Kandemirli, N. Caner and I. Love, Int. J. Quantum Chem., 110, 1003 (2010); https://doi.org/10.1002/qua.22249.

33. G. Gece and S. Bilgic, Corros. Sci., 52, 3435 (2010); https://doi.org/10.1016/j.corsci.2010.06.015.

34. S. Xia, M. Qiu, L. Yu, F. Liu and H. Zhao, Corros. Sci., 50, 2021 (2008); https://doi.org/10.1016/j.corsci.2008.04.021.

35. H. Wang, X. Wang, H. Wang, L. Wang and A. Liu, J. Mol. Model., 13, 147 (2006); https://doi.org/10.1007/s00894-006-0135-x. 